\title{
Catamnestic Observation of Premature Newborns with Nervous System Injury in the Kyrgyz Republic
}

\author{
Aisuluu Omurzakova', Aida Anarbaeva² ${ }^{2}$ Zhainagul Abdirasulova1, Feruza Mamasadykova', \\ Zhazgul Eralieva1, Guldana Tashieva1, Kamchybek Uzakbaev ${ }^{3}$, Gulshat Matkasymova4,

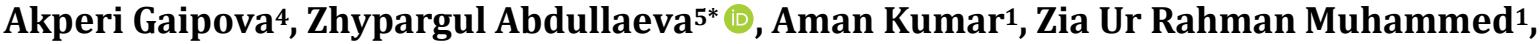 \\ Abhishek Anand ${ }^{1}$

\footnotetext{
${ }^{1}$ Department of Clinical Disciplines 2, International Medical Faculty, Osh State University, Osh, Kyrgyzstan

${ }^{2}$ Department of Pediatric Surgery, Medical Faculty, Osh State University, Osh, Kyrgyzstan

${ }^{3}$ Maternity and Child Welfare National center under Ministry of Health, Bishkek, Kyrgyzstan

${ }^{4}$ Department of Surgical Disciplines and Traumatology, International Medical Faculty, Osh State University, Osh, Kyrgyzstan

${ }^{5}$ Science and Research Department, Osh State University, Osh, Kyrgyzstan

Email: *jypar.science@oshsu.kg
}

How to cite this paper: Omurzakova, A., Anarbaeva, A., Abdirasulova, Z., Mamasadykova, F., Eralieva, Z., Tashieva, G., Uzakbaev, K., Matkasymova, G., Gaipova, A., Abdullaeva, Z., Kumar, A., Muhammed, Z.U.R. and Anand, A. (2021) Catamnestic Observation of Premature Newborns with Nervous System Injury in the Kyrgyz Republic. Open Journal of Pediatrics, 11, 189-197.

https://doi.org/10.4236/ojped.2021.112018

Received: March 14, 2021

Accepted: May 23, 2021

Published: May 26, 2021

Copyright $\odot 2021$ by author(s) and Scientific Research Publishing Inc. This work is licensed under the Creative Commons Attribution International License (CC BY 4.0).

http://creativecommons.org/licenses/by/4.0/

\begin{abstract}
Background: Recently, among child disability disorders nervous system diseases are prevailing 19.5\%, while mental disorders are $14.3 \%$ and congenital malformations $21 \%$. In most cases, children's neurological disability is associated with pathology during the perinatal period, while $24 \%$ of patients have a cerebral impairment. Premature newborns perished 30 to 35 times more often than in-time newborns, and perinatal mortality in case of premature pregnancies is 30 to 40 times higher than in term delivery. Aim: This article is studying catamnestic observation of premature newborns with nervous system injury and with perinatal pathology in Kyrgyzstan for the period 2020-2021. Preterm newborns' anthropometric characteristics and main diagnoses associated with diseases in the gestational period were shown. Methods: A comprehensive clinical and laboratory examination including premature newborns health dynamic monitoring with gestational age from 28 to 36 weeks, who were treated in the neonatal pathology department of the Regional Maternity Hospital in Osh for the period from 2020-2021 were carried out. Literature review analysis from PubMed database, MEDLINE, EMBASE, Science Direct, Google Scholar, and clinical trials performed. Results: after clinical examination, it was revealed that pregnancy and childbirth in all mothers of the studied group passed with complications. In mothers of the studying group, the most common pathologies during pregnancy were chronic fetal hypoxia $49(58.4 \%)$, acute respiratory infections 28 (33.4\%), the threat of ter-
\end{abstract}


mination of pregnancy 20 (23.9\%), preeclampsia $16(19.11 \%)$, sexually transmitted infections $9(10.8 \%)$, pyelonephritis $14(16.7 \%)$, polyhydramnios 9 (10.8\%), 71 children (84.6\%) were born with asphyxiation and 25 children extracted by cesarean section with varying degrees of severity. Conclusions: Depending on the severity of the perinatal lesion of the nervous system and pathological factor effects, it is very important to start early habilitation measures with preterm newborns who are at risk of developmental delay deviations, and to exit disabling disorders.

\section{Keywords}

Catamnestic Observation, Premature Newborns, Nervous System, Injury, Pathology

\section{Introduction}

Most common neurological disorders in newborns are associated with acute symptomatic phenomena, the main etiologies being intraventricular hemorrhage, hypoxic-ischemic encephalopathy prevalent in preterm than in full-term infants [1]. During delivery, newborns' heads were influenced by contractions of the uterine muscles and intra-abdominal pressure that cause physiological or enduring pathological changes to the skull [2]. Brain injury in newborn infants with asphyxia may be progressed under delayed restoration of cardiac output and oxygen delivery; also, in association with high arterial pressure and cerebral blood flows caused by the restoration of cardiac output [3]. Preterm birth can be associated with a high risk of morbidity, mortality and brain damage (Figure 1) with cerebral palsy; brain injury development in preterm newborns caused due to factors such as perinatal asphyxia, infection/inflammation, and chronic hypoxia [4].

Diseases of the nervous system prevail $19.5 \%$, mental disorders $14.3 \%$ and congenital malformations $21 \%$ among child disability disorders; in $60 \%$ of cases, children's neurological disability is associated with the pathology of the perinatal period, while $24 \%$ are patients with cerebral palsy [5] [6]. Cerebral palsy (CP) includes a group of disorders in movement and posture development, that are attributed to nonprogressive impairments during the development of fetal or infant brain, later characterized by disturbances of sensation, perception, cognition, communication, and behavior [7] [8]. Preterm newborns die 30 - 35 times more often than infants born on time, and perinatal mortality in premature pregnancies [9] is 30 - 40 times higher than in term delivery. However, for decades, perinatal and infant mortality in the world [10] has been steadily declining.

Over the past years in Kyrgyzstan, according to the research results presented at the round table dedicated to the celebration of Convention on the Child Rights "Survival of newborns in Kyrgyzstan: achievements and ways to improve", which assesses the trends in neonatal mortality across the country over the past 


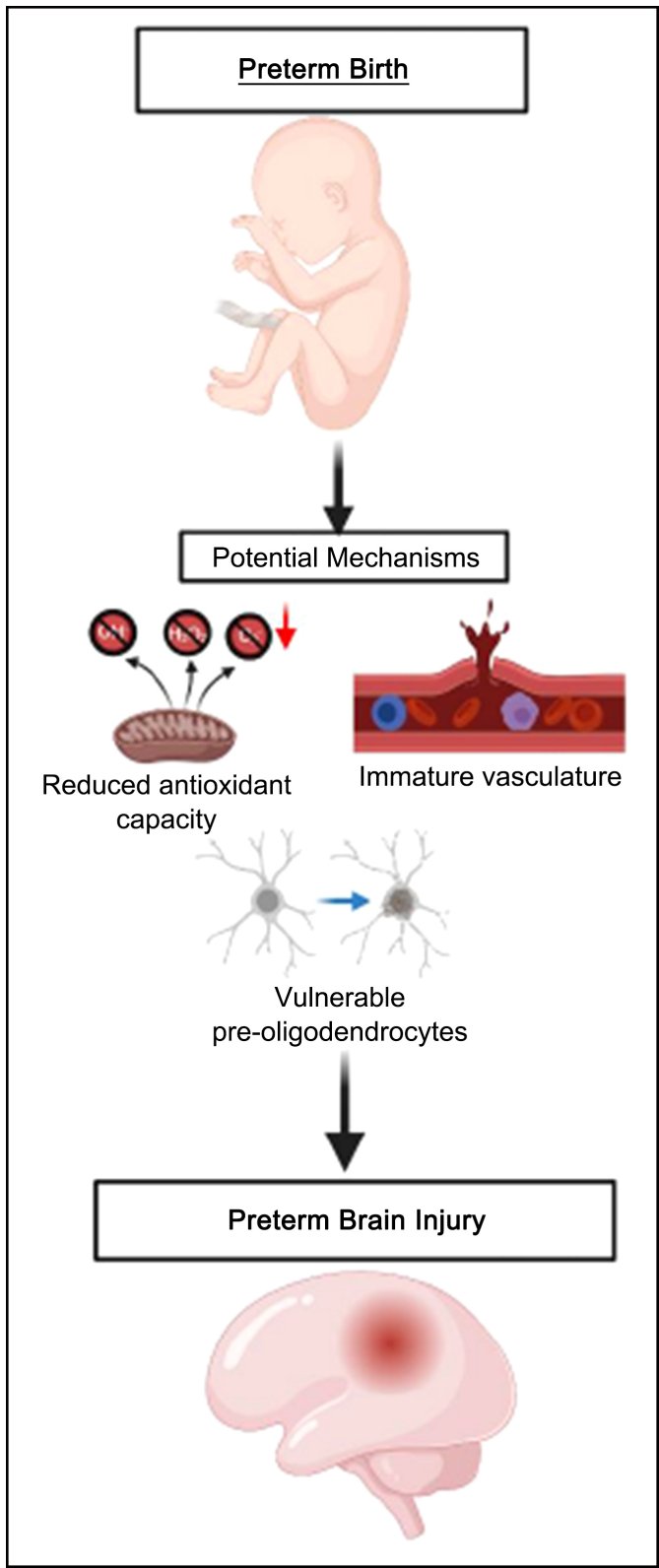

Figure 1. Potential factors contributing to preterm brain injury.

28 years (1990-2018) showed that perinatal mortality in the Kyrgyz Republic from 1990 to 2018 decreased for 24.0 deaths per 1000 live births; in 1991 decreased to 10.7 deaths; in 2017 year this indicator was 54\%. According to obtained results, between diseases that cause infant mortality, the perinatal hypoxic brain lesions in the perinatal period have prevailed. After which the congenital anomalies and diseases of the respiratory system were circulated.

But along with a decrease in infant mortality rate and despite the treatment of pregnant women, modern technologies for prolonging pregnancy, the frequency of preterm birth has not been decreased over the past two decades [11] [12], as was evidenced by the results of WHO report published in November 2015, 15 
million premature newborns delivered annually, and this number is increasing every year. In Kyrgyzstan, about 10 - 12 thousand infants were born preterm every year.

In recent years, there has been progressed in the development of highly effective neonatal technologies (provision of primary resuscitation care to a newborn in the delivery room, antenatal prevention of respiratory distress syndrome in premature babies), modern equipment of perinatal centers. The number of surviving premature babies has increased remarkably. Among the surviving children, no more than $10 \%-25 \%$ are healthy infants. The number of children with severe neuropsychiatric disorders can reach $12 \%$ to $19 \%$. Premature newborns $50 \%$ have neurological diseases, including cerebral palsy, visual impairment and blindness, hearing and severe chronic lung diseases [13]. Despite the measures taken to reduce the risk of severe complications and mortality among premature infants, recently, there is no tendency to reduce the level of disability among preterm newborns with the consequences of perinatal pathology; they are children with serious pathology of the nervous system.

According to the government statistical service, by 2016 the number of children with disabilities in Kyrgyzstan were 28 thousand, which is more than in 2011 year to 5 thousand or $16 \%$. Nowadays, there are over 29 thousand children under 18 years with disabilities, and most common disease among them is cerebral palsy. Therefore, it is important not only the child's survival, but also the possibility of his subsequent normal development. One of the methods in restorative treatment is the use of early medical interventions, which are aiming at early assistance to children with developmental delay, where specialists from various fields (pediatrician, abilitologist, physical therapists, teachers, psychologists, speech therapists) are involved, and providing specific assessment for the child condition, and the use of a set of activities for the normal child development. This work objectives were comprehensive clinical and laboratory examination with dynamic monitoring of health in premature infants with gestational age from 28 to 36 weeks, who were treated in the neonatal intensive care unit in the Osh Regional Maternity Hospital.

\section{Research Methods and Materials}

Criteria for the inclusion of newborns in the study include 1) gestational age up to 37 weeks; 2) body weight at birth is not more than 2500 grams; 3) the presence of neurological symptoms. Criteria for dividing children into groups include gestational age and the presence or absence of intrauterine growth retardation (IUGR). Maturity degree determination in premature newborns, corresponding to a certain gestational age carried out according to the modified Ballard scale [14]. Fetal growth retardation was diagnosed in children with low birth weight in relation to their gestational age when the body weight was below $10 \%$ comparing to the mothers' body weight. Based on the selected criteria, all newborns were divided by gestational age into 5 groups (Table 1 ). 
Table 1. Distribution of premature newborns into groups.

\begin{tabular}{cccc}
\hline Groups & $\begin{array}{c}\text { Gestational } \\
\text { age (weeks) }\end{array}$ & $\begin{array}{c}\text { Intrauterine growth retardation } \\
\text { (IUGR) or appropriate for } \\
\text { gestational age (AGA) }\end{array}$ & $\begin{array}{c}\text { Quantity } \\
\text { (abs. \%) }\end{array}$ \\
\hline I & Before 28 & AGA & $3(3.5 \%)$ \\
II & $28-31$ & AGA & $38(36.9 \%)$ \\
III & $28-31$ & IUGR & $8(9.52 \%)$ \\
IV & $32-36$ & AGA & $21(25 \%)$ \\
V & $32-36$ & IUGR & $14(16.6 \%)$ \\
\hline
\end{tabular}

As it is shown in Table 1 newborns with intrauterine growth retardation (IUGR) accounted for (III + V group) were $26.12 \%$. The examination of newborns included the use of clinical, instrumental and laboratory techniques, which were carried out upon admission to the intensive care unit for premature infants.

A comprehensive clinical and laboratory examinations including dynamic monitoring of 84 premature newborns health with gestational age from 28 to 36 weeks, who treated in the neonatal pathology department of the Regional Maternity Hospital in Osh for 2020 to 2021 carried out. Literature review analysis from PubMed database, MEDLINE, EMBASE, Science Direct, The Cochrane Database, Google Scholar, and clinical trials performed. According to the examination protocols, the following diagnostic measures made:

1) Collection of anamnesis data, pregnancy course analysis, childbirth, mothers obstetric and gynecological history and somatic health, assessment of the newborns' adaptation period;

2) Clinical examination of organs and systems including anthropometric examination at admission: body weight, length, head circumference, chest measurements;

3) Standard laboratory tests (general clinical blood test, general urinalysis, coprogram, biochemical blood test for glucose, total bilirubin, direct and indirect, total protein, electrolytes and urea content;

4) Brain ultrasound examination: neurosonography, dopplerography; application of instrumental research methods such as neurosonography (NSG) and electroencephalography (EEG), neurological status assessment;

5) Use of diagnosing methods for intrauterine infections (polymerase chain reaction, enzyme immunoassay for intrauterine infections with determination of the IgG and IgM concentrations);

6) Examination by specialists (neurologist, pediatrician, infectious disease specialist and ophthalmologist);

7) Clinical examination, including examination, palpation, percussion, auscultation of newborns, anthropometric measurements, laboratory diagnostics, ultrasound examination of the brain, chest $\mathrm{x}$-ray, ophthalmological examination, 
consultation with a neurologist.

For assessment of neurological status, the classification of perinatal lesions of the central nervous system in newborns was used [15]. During an external examination, the general spontaneous motor activity, its symmetry, volume of active and passive movements, the state of consciousness, voice reactions (groaning, the presence or absence of a cry), the child's posture, the presence of physiological and pathological reflexes, the proportionality of the physique, the shape of the skull, the state of the cranial sutures were assessed. During skin examination, the color change (pallor, yellowness, marbling, grayish tint), maceration, the presence of hemorrhages, body temperature were taken into account. Examination by systems carried out according to generally accepted standards.

Catamnestic observation of examined children carried out in 2020-2021, based on the study of ambulatory cards. Statistical analysis of the research results carried out using the analytical package Statistica 6.0.

\section{Results and Discussions}

The study includes 84 preterm infants with gestational age from 28 to 36 weeks. Criteria for the inclusion of newborns in the study: 1) Gestational age up to 37 weeks; 2) Body weight at birth is not more than 2500 grams; 3) The presence of neurological symptoms. Anthropometric studies are important for the diagnosis of perinatal lesions of the central nervous system. When studying the indicators of physical development, the following methods were used to determine the body weight at birth, length, head and chest circumference according to the method by [16]. Anthropometric indicators of children in the group under study were presented in Table 2.

In mothers of the studying group, the most common pathologies during pregnancy were chronic fetal hypoxia 49 (58.4\%), acute respiratory infections 28 $(33.4 \%)$, the threat of termination of pregnancy $20(23.9 \%)$, preeclampsia 16 (19.11\%), sexually transmitted infections 9 (10.8\%), pyelonephritis $14(16.7 \%)$, polyhydramnios 9 (10.8\%). 25 children extracted by cesarean section with varying degrees of severity, and 71 children (84.6\%) were born with asphyxiation, on the Apgar scale ranged from 2 to 7 points. The children number on the ventilator were $53(63.1 \%)$, duration of mechanical ventilation was 2 weeks. All resuscitation measures were carried out following clinical protocols for neonatology approved by the Kyrgyz Republic Ministry of Health protocol No. 104 from February 10, 2016, under recommendations of the American Academy of Pediatrics and the American Association of Cardiologists.

Based on the examination and treatment in the neonatal intensive care unit, the following diagnoses were determined (Table 3): infection specific to the perinatal period $32.14 \%$ of cases, cerebral nontraumatic hemorrhage $9.52 \%$ and respiratory distress syndrome with outcome in bilateral pneumonia $22.61 \%$, encephalopathy of mixed genesis $25 \%$, multiple congenital malformations of the central nervous system $8.3 \%$, and microcephaly $2.38 \%$. 
Table 2. Anthropometric indicators of children of the study group.

\begin{tabular}{ccc}
\hline & \multicolumn{2}{c}{ Gestation term (week) } \\
\cline { 2 - 3 } Indicators & $28-31(\mathrm{n}=22)$ & $31-36(\mathrm{n}=62)$ \\
\hline Body weight at birth $(\mathrm{g})$ & $1155.625 \pm 40.830$ & $1333.72 \pm 62.35$ \\
Body length at birth $(\mathrm{cm})$ & $36.25 \pm 0.96$ & $40.043 \pm 0.699$ \\
Head circumference $(\mathrm{cm})$ & $25.375 \pm 0.380$ & $27.390 \pm 0.319$ \\
Chest circumference $(\mathrm{cm})$ & $23.50 \pm 0.73$ & $25.043 \pm 0.460$ \\
\hline
\end{tabular}

Table 3. The structure of morbidity in children of the study group.

\begin{tabular}{ccc}
\hline \multirow{2}{*}{ Diagnosis (main) } & \multicolumn{2}{c}{ Gestation term (week) } \\
\cline { 2 - 3 } & $28-31(\mathrm{n}=22)$ & $31-36(\mathrm{n}=62)$ \\
\hline Infection specific for the perinatal period & $11(50 \%)$ & $5(8.07 \%)$ \\
Cerebral non-traumatic hemorrhage & $3(13.7 \%)$ & $15(24.2 \%)$ \\
$\begin{array}{c}\text { Respiratory distress syndrome with } \\
\text { outcome in bilateral pneumonia } \\
\begin{array}{c}\text { Multiple congenital malformations of } \\
\text { the central nervous system }\end{array}\end{array}$ & $4(18.2 \%)$ & $5(8.07 \%)$ \\
Encephalopathy of the newborn & $2(9.1 \%)$ & $19(30.7 \%)$ \\
Microcephaly & $2(9.1 \%)$ & $2(3.8 \%)$ \\
\hline
\end{tabular}

In addition to the underlying disease, $38.09 \%$ of newborns in the study group had concomitant pathology: retinopathy of prematurity I - II degree were 5 (5.9\%), anemia of prematurity 45 (53.57\%), and prematurity rickets $42(50,9 \%)$. When assessing the neurological status, the majority of newborns were dominated by the syndrome of CNS depression 35 (41.6\%) and further (in descending order): hyperexcitability syndrome 15 (17.8\%), hypertensive-hydrocephalic 9 (10.7\%), convulsive syndrome 5 (5.95\%). A combination of syndromes observed in $8.25 \%$ of examined patients. During neurosonography, 29 children (34.5\%) revealed structural changes in the periventricular zone, the ventricular system of the brain and the white matter: IVH grade I in 14 (48.3\%), IVH grade II in $6(20.7 \%)$, IVH grade III in $6(24 \%)$, IVH grade IV in $3(12 \%)$, periventricular cysts were detected in $3(12 \%)$, and periventricular leukomalacia (PVL) in 2 (8\%). In $3(12 \%)$ of the examined children, the lesion was bilateral, in $4(16 \%)$ there was a combination of disorders in the structure of the brain tissue (PVL, periventricular cysts, etc.) and hemorrhagic lesions (IVH) of varying degrees.

After clinical examinations, it was revealed that pregnancy and childbirth in all mothers of the studied group proceed with complications. Considering the dominant CNS damage in children with very low birthweight (VLBW) and extremely low birthweight (ELBW) at birth, high nursing costs, their further phys- 
ical and neuropsychic development is of great interest. In every third child, a low level of neuropsychic and physical development was observed. According to the literature, premature infants with extremely low body mass weight, on average, have lower grades of academic performance, which is due to difficulties in reading and correct pronunciation, as well as in arithmetic study [17]. Therefore, questions in early diagnosis of severe cerebral nervous system disorders with their timely identification, psychological and pedagogical support of children in this group are still relevant.

Currently, premature newborns are out of scope in psychological, medical and pedagogical checks, as they are observing in the children's clinics, where diagnostics with consequent correctional assistance may not provide. The above data indicates creation and need for a unified program for early diagnosis and correction of nervous system lesions in premature infants.

\section{Conclusions}

Based on the above research results the following conclusions were made:

1) Deep gestational immaturity in combination with intrapartum asphyxia and an infectious component to determine the complicated course of the early adaptation period. Developing respiratory and hemodynamic disorders, hypoxemia, acidosis become the main risk factors for severe cerebral injuries with an unfavorable outcome.

2) A direct relationship was established between unfavorable somatic and neurological outcomes in children with extremely low birth weight in critical conditions of the early neonatal period.

3) Timely diagnosis and restorative correction are of great importance, which is affecting quality of life and subsequent development of prematurely born children who have undergone perinatal encephalopathy. Depending on the severity of the perinatal lesion of the nervous system and the nature of effects of the pathological factor, it is very important to start early habilitation measures with children who are at risk of developmental delay and deviations.

\section{Conflicts of Interest}

The authors declare no conflicts of interest regarding the publication of this paper.

\section{References}

[1] Spagnoli, C., Falsaperla, R., Deolmi, M., Corsello, G. and Pisani, F. (2018) Symptomatic Seizures in Preterm Newborns: A Review on Clinical Features and Prognosis. Italian Journal of Pediatrics, 44, Article No. 115. https://doi.org/10.1186/s13052-018-0573-y

[2] Rabelo, N.N., Matushita, H. and Cardeal, D.D. (2017) Traumatic Brain Lesions in Newborns. Arquivos de Neuro-Psiquiatria, 75, 180-188. https://doi.org/10.1590/0004-282x20170016

[3] Badurdeen, S., Roberts, C., Blank, D., Miller, S., Stojanovska, V., Davis, P., Hooper, 
S. and Polglase, G. (2019) Haemodynamic Instability and Brain Injury in Neonates Exposed to Hypoxia-Ischaemia. Brain Sciences, 9, 49. https://doi.org/10.3390/brainsci9030049

[4] Yates, N., Gunn, A.J., Bennet, L., Dhillon, S.K. and Davidson, J.O. (2021) Preventing Brain Injury in the Preterm Infant-Current Controversies and Potential Therapies. International Journal of Molecular Sciences, 22, 1671. https://doi.org/10.3390/ijms22041671

[5] Barkun, G.K., Lysenko, I.M., Zhuravleva, L.N., Kosenkova, E.G. and Buchkina, T.I. (2013) Follow-Up of Children with Very Low and Extremely Low Birth Weight. Bulletin of Vitebsk State Medical University, 12, 63-69.

[6] Kulakov, V.I. and Barashnev, Y.I. (2006) High-Risk Newborns: New Diagnostic and Treatment Technologies. Moscow: Geotar-Media, 270.

[7] Agarwal, A. and Verma, I. (2012) Cerebral Palsy in Children: An Overview. Journal of Clinical Orthopaedics and Trauma, 3, 77-81.

https://doi.org/10.1016/j.jcot.2012.09.001

[8] Gulati, S. and Sondhi, V. (2018) Cerebral Palsy: An Overview. Indian Journal of Pediatrics, 85, 1006-1016. https://doi.org/10.1007/s12098-017-2475-1

[9] Joseph, K.S., Razaz, N., Muraca, G.M. and Lisonkova, S. (2017) Methodological Challenges in International Comparisons of Perinatal Mortality. Current Epidemiology Reports, 4, 73-82. https://doi.org/10.1007/s40471-017-0101-4

[10] Deb-Rinker, P., León, J.A., Gilbert, N.L., Rouleau, J., Andersen, A.M., Bjarnadóttir, R.I., Gissler, M., Mortensen, L.H., Skjærven, R., Vollset, S.E., Zhang, X., Shah, P.S., Sauve, R.S., Kramer, M.S. and Joseph, K.S. (2015) Differences in Perinatal and Infant Mortality in High-Income Countries: Artifacts of Birth Registration or Evidence of True Differences? BMC Pediatrics, 15, 112. https://doi.org/10.1186/s12887-015-0430-8

[11] Shchepin, O.L. and Tishuk, E.A. (2001) Current State and Trends in Morbidity of the Population of the Russian Federation. Russian Federation Healthcare, 1, 3-10.

[12] Malofeev, N.N. and Uryadnitskaya, N.A. (2007) On the Development of an Early Assistance Service for a Family with a Problem Child in the Russian Federation. Defectology, 6, 60-68.

[13] Kulakov, V.I., Antonov, A.G. and Baybarina, E.N. (2006) Problems and Prospects of Nursing Children with Extremely Low Body Weight at the Present Stage. Russian Bulletin of Perinatology and Pediatrics, 4, 8-11.

[14] Ballard, J.L., Novak, K.K. and Driver, M. (1979) A Simplified Score for Assessment of Fetal Maturation of Newly Born Infants. The Journal of Pediatrics, 95, 769-774. https://doi.org/10.1016/S0022-3476(79)80734-9

[15] Volodin, H.H. (2004) New Approaches to the Diagnosis of Perinatal Lesions of the Nervous System in Children of the First Year of Life and Their Classification. Pediatrics, 1, 5-9.

[16] Usov, I.N., Chichko, M.V. and Astakhova, L.N. (1990) Practical Skills of a Pediatrician. Textbook. Minsk: Higher School, 400.

[17] Marlow, N., Roberts, L. and Cooke, R. (1993) Outcome at 8 Years for Children with Birth Weights of $1250 \mathrm{~g}$ or Less. Archives of disease in childhood, 68, 286-290.

https://doi.org/10.1136/adc.68.3_Spec_No.286 